\title{
Diminuição do volume de lodo de estação de tratamento de águas usando leito de drenagem
}

\section{Decrease in the sludge volume from a water treatment plant using drainage bed}

Renan Gabriel Condé Santos ${ }^{1}$, Bruna Ribeiro Vieira ${ }^{2}$, Gabrielle Louize Lopes Esteves ${ }^{3}$, Leticia Ferreira de Oliveira ${ }^{4}$, Luiz Gustavo Santos Miguel ${ }^{5}$, Maria Eduarda Leão Dutra ${ }^{6}$, Marcelo da Silva Batista7

\section{RESUMO}

O leito de drenagem tem sido estudado para recuperação de águas residuais e redução de volume de lodo industrial de Estações de Tratamento de Água (ETA). Este trabalho tem como objetivo avaliar o uso de leito de drenagem para a desidratação de lodo da ETA da cidade de Ouro Branco/MG. Amostras de lodo foram coletadas no decantador da ETA e passaram por um leito de drenagem construído com tubo PVC, manta geotérmica e brita. Foram analisados o volume inicial e final do lodo, cor, $\mathrm{pH}$, teor total de sólidos, turbidez, teor de alumínio e o tempo total de secagem do lodo. Os resultados mostraram a diminuição do volume de lodo com recuperação de $98 \%$ da água e retenção de $99,91 \%$ dos sólidos totais no leito com torta colmatada. A água drenada apresentou redução de 99,36\% na turbidez, 0,05 mg/L de alumínio, melhoria na cor e $\mathrm{pH}=6-7$.

Palavras-chave: Desaguamento de lodo; leito de drenagem; recuperação de água; redução de volume de lodo.

\section{ABSTRACT}

The drainage bed has been studied to recover wastewater and reduce the volume of industrial sludge from Water Treatment Plants (WTP). This study aims to evaluate the use of a drainage bed for WTP sludge dewatering in the city of Ouro Branco/MG. Sludge samples were collected in the ETA decanter and passed through a drainage bed constructed with PVC pipe, geothermal blanket and gravel. Initial and final sludge volume, color, $\mathrm{pH}$, total solids content, turbidity, aluminum content and total sludge drying time were analyzed. The results showed a decrease

\footnotetext{
${ }^{1}$ Universidade Federal de São João del-Rei - UFSJ, Ouro Branco/MG - Brasil. E-mail: renan2801@gmail.com

${ }^{2}$ Idem. E-mail: bruna.ribeirov@gmail.com

${ }^{3}$ Idem. E-mail: gabrielle.llopes@yahoo.com.br

${ }^{4}$ Idem. E-mail: leferreira1195@gmail.com

${ }^{5}$ Idem. E-mail: luizgustavomiguel@gmail.com

${ }^{6}$ Idem. E-mail: eduardaleaodutra@gmail.com

${ }^{7}$ Departamento de Engenharia Química - DEQUI, Universidade Federal de São João del-Rei - UFSJ, Ouro Branco/MG - Brasil. E-mail: marcelobatista@ hotmail.com
} 
in sludge volume with $98 \%$ water recovery and $99.91 \%$ retention of total solids in the bed with cake. Drained water showed $99.36 \%$ reduction in turbidity, $0.05 \mathrm{mg} / \mathrm{L}$ aluminum, color improvement and $\mathrm{pH}=6-7$.

Keywords: Sludge dewatering; drainage bed; water recovery; sludge volume reduction.

\section{INTRODUÇÃO}

O lodo de decantadores e a água de lavagem de filtros são os principais resíduos gerados nas Estações de Tratamento de Água (ETA) que possuem tecnologia de ciclo completo. (KURODA et al., 2014). As principais perdas de água ocorrem devido à necessidade de limpeza das unidades de tratamento para remoção de resíduos (lavagem de floculadores, decantadores e filtros) e vazamentos nas unidades e/ou tubulações. (ACHON et al., 2013). O lodo é definido como resíduo sólido, e, portanto, deve estar em consonância com os preceitos da Lei 12.305/2010 (BRASIL, 2010) e da série de normas NBR 10.004/2004, elaboradas pela ABNT (2004).

A composição do lodo de ETAs é muito complexa e formada por partículas pequenas com arranjo que pode dificultar a remoção de água. (WASSERMAN et al., 2019). Além disso, a sedimentação das partículas, que passam a ocupar os vazios da massa sólida, dificulta a passagem da água livre. Como o volume de lodo produzido pelas ETAs é elevado, a destinação direta em aterros torna-se inviável. (SILVEIRA, 2012). Nesse sentido, um dos problemas mais sérios é a redução do volume de lodo gerado nas ETAs. Esta redução pode ser realizada com a remoção da água livre e nos interstícios dos sólidos através de sistemas naturais ou mecânicos. (RAFIQUE et al., 2019). A remoção natural de água livre dos resíduos de ETAs pode ser realizada por sistemas naturais de redução de volume, que são as lagoas de lodo e os leitos de drenagem. A tecnologia de leitos de drenagem tem sido utilizada desde o início do século XX e, então, vem sendo aplicada praticamente sem mudanças consideráveis em sua estrutura física. Nos sistemas tradicionais a estrutura é formada basicamente de: camada suporte; meio filtrante e sistema dreno. (ACHON et al., 2008). Vale salientar que, esse sistema de tratamento de resíduos de ETAs possui grande potencial de aplicação, principalmente devido a disponibilidade de área, condições climáticas favoráveis e por ser um sistema de baixo custo, que não necessita de produtos químicos e energia elétrica.

Nesse contexto, esse trabalho tem por objetivo avaliar o uso de leito de drenagem para o desaguamento de lodos provenientes da Estação de Tratamento de Água da cidade de Ouro Branco, Minas Gerais. Para isso, foi construído um leito de drenagem para avaliar a redução de volume de lodo e água recuperada, mudanças de cor, pH, concentração de sólidos totais, turbidez e o teor de alumínio na água residual. 


\section{DESENVOLVIMENTO}

\subsection{METODOLOGIA}

A Figura 1 mostra o leito de drenagem formado por um tubo PVC (Policloreto de Vinila) de $20 \mathrm{~cm}$ de diâmetro e $50 \mathrm{~cm}$ de altura, uma camada de manta geotêxtil e uma camada de brita número 0 .

Figura 1 - Dimensões e materiais do leito de drenagem.

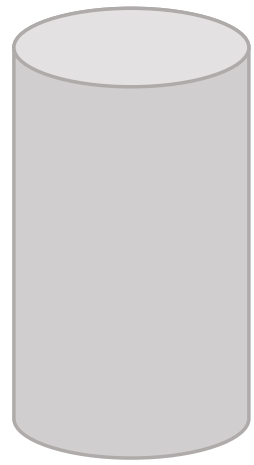

Tubo PVC

Altura: $50 \mathrm{~cm}$

Diâmetro: $20 \mathrm{~cm}$
Manta Geotêxtil

Espessura: 4,5 mm

Porosidade: maior que $90 \%$

Cama de brita $\mathrm{n}^{\circ} 0$

Altura: 4 a $5 \mathrm{~cm}$

Fonte: Elaborada pelos autores.

A Tabela 1 mostra as características da manta geotêxtil utilizada na construção do leito. Foram coletados, em março e junho de 2019, dois lotes de $30 \mathrm{~L}$ de amostra de lodo no decantador da ETA de ciclo completo, do município de Ouro Branco - MG. Nos ensaios, analisou-se a concentração de sólidos ao longo do tempo, volume de lodo, volume de água drenada e o tempo de remoção da água do lodo. Após os ensaios, a manta foi retirada com a massa seca de sólidos. A massa seca de sólidos foi coletada e caracterizada quanto à concentração final de sólidos.

Tabela 1 - Especificações da manta geotêxtil.

\begin{tabular}{lll}
\hline Características & Unidades & Valores \\
\hline Espessura & $\mathrm{mm}$ & 4,5 \\
Porosidade & $\%$ & $>90$ \\
Permeabilidade normal & $\mathrm{cm} / \mathrm{s}$ & $3 \times 10^{-1}$ \\
Abertura & $\mathrm{um}$ & 60 \\
Densidade superficial & $\mathrm{g} / \mathrm{m}^{2}$ & 600 \\
\hline
\end{tabular}

Fonte: Elaborada pelos autores.

Na caracterização do lodo e da água residual foram utilizados métodos padronizados de análises. (EATON et al., 1998). Para avaliação do desempenho do sistema de drenagem foram analisados: volume inicial e final do lodo, cor, $\mathrm{pH}$, teor de sólidos totais no lodo, teor de sólidos totais na amostra drenada, turbidez e quantidade de alumínio presente na água residual. (ACHON et al., 2013; SILVEIRA, 2012). Foi 


\section{Revista Thema}

analisado, também, o tempo de drenagem (desaguamento) e a quantidade de água drenada.

\subsection{RESULTADOS E DISCUSSÃO}

Na Tabela 2 são apresentadas as características do primeiro lote de lodo coletado em março. Note que o lodo apresenta alta concentração de sólidos suspensos e elevada turbidez e, o grande volume de lodo da ETA aumenta o custo para descarte.

Tabela 2 - Características do primeiro lote de lodo antes da drenagem.

\begin{tabular}{lll}
\hline Parâmetro & Unidades & Valores \\
\hline Turbidez & NTU & 190 \\
pH & - & 6,7 \\
Sólidos suspensos & $\mathrm{g} / \mathrm{L}$ & 2,45 \\
Cor & - & Amarelo escuro \\
\hline
\end{tabular}

Fonte: Elaborada pelos autores.

No leito de drenagem (Figura 1 ) foram inseridos 5,22 L do primeiro lote de lodo (Tabela 2) e acompanhada a redução de seu volume em função do tempo. A Figura 2 mostra o volume de água drenada em função do tempo. Foi observada uma redução de mais de $50 \%$ do volume do lodo nos primeiros 5 min de operação. Esse resultado está de acordo com o observado por Cordeiro (2008), que apresentaram redução de $42 \%$ do volume dentro do mesmo período de tempo. Depois de 20 min de operação, o volume de água drenada começa a se estabilizar. A drenagem foi finalizada em cerca de 40 min após o volume de água drenada não modificar.

Figura 2 - Volume de água drenada versus o tempo de drenagem.

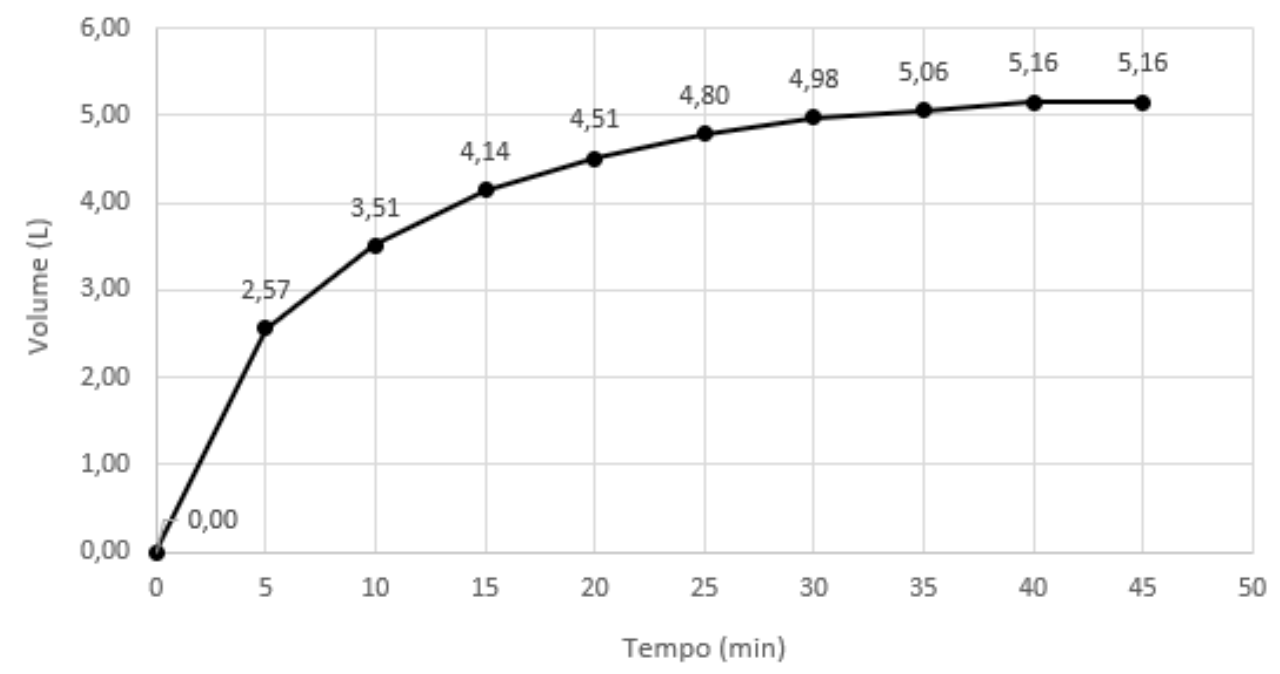

Fonte: Elaborada pelos autores.

Foi observado que a água não ficou empossada no leito e o volume de sólido que permaneceu no leito foi de $0,063 \mathrm{~L}$, sendo formado maioritariamente por partículas sólidas. A Tabela 3 mostra os resultados de turbidez, pH, sólidos suspensos e cor da água drenada e, os parâmetros estabelecidos na resolução do CONAMA № 020/1986. 
Note que houve redução de $98 \%$ do volume de lodo colocado no leito de drenagem. O sistema apresentou eficiência de $64 \%$ para remoção de sólidos. No entanto, os valores de $\mathrm{pH}$ e turbidez estão de acordo com a resolução do CONAMA, porém, ainda é necessário a diminuição de sólidos suspensos e tornar incolor a cor da água drenada.

Tabela 3 - Característica da água drenada e Resolução do CONAMA.

\begin{tabular}{lll}
\hline Parâmetro & Resultado Obtido & Resolução Conama \\
\hline Turbidez & $19,5 \mathrm{NTU}$ & $\leq 40 \mathrm{NTU}$ \\
$\mathrm{pH}$ & 6,9 & Entre 6,0 e 9,0 \\
Sólidos Suspensos & $0,88 \mathrm{~g} / \mathrm{L}$ & $\leq 0,5 \mathrm{~g} / \mathrm{L}$ \\
Cor & Amarelo claro & incolor \\
\hline
\end{tabular}

Fonte: Elaborada pelos autores.

A Tabela 4 mostra os resultados de turbidez, pH, sólidos suspensos e cor do segundo lote de lodo coletado em junho. Note que nesse segundo lote o lodo apresenta valores muito maiores de turbidez e sólidos suspensos, comparado com o primeiro lote (Tabela 1). Esse segundo ensaio de drenagem foi realizado com 8,0 $\mathrm{L}$ do segundo lote de lodo. O lodo foi passado em cima da torta colmatada, decorrente do primeiro ensaio.

Tabela 4 - Característica do segundo lote de lodo antes da drenagem.

\begin{tabular}{lll}
\hline Parâmetro & Unidades & Valores \\
\hline Turbidez & NTU & 430 \\
pH & - & 6,2 \\
Sólidos suspensos & $\mathrm{g} / \mathrm{L}$ & 20 \\
Cor & - & Amarelo escuro \\
\hline
\end{tabular}

Fonte: Elaborada pelos autores

A Figura 3 mostra a redução de volume de lodo em função do tempo. Foi observada uma redução mais lenta do volume de lodo em relação ao primeiro ensaio. Note que o volume de água drenada começa a se estabilizar após $1400 \mathrm{~min}$ de operação. A drenagem foi finalizada após 1680 min (1 dia e 4 h). Note que houve redução de $91 \%$ do volume de lodo colocado no leito de drenagem. Foi observado que a água não ficou empossada no leito e o volume de sólido que permaneceu no leito foi de 0,659 L.

A Tabela 5 mostra os resultados de turbidez, $\mathrm{pH}$, sólidos suspensos e cor da água drenada no segundo ensaio. Note que a água drenada apresenta valores maiores de turbidez e sólidos suspensos, comparada com o primeiro ensaio (Tabela 3). No entanto, o sistema apresentou eficiência de $87 \%$ na remoção de sólidos, que foi superior ao primeiro ensaio (64\%).

O terceiro ensaio de drenagem foi realizado com um volume de $11,0 \mathrm{~L}$ de lodo do segundo lote (Tabela 4). O lodo foi inserido no leito de drenagem em cima da torta já existente, decorrente do primeiro e segundo ensaios. A Figura 4 mostra o volume de água drenada em função do tempo. Note que a redução do volume de lodo foi mais lenta em relação ao primeiro e segundo ensaios, isto pode estar relacionado com a 


\section{Revista Thema}

V.19

maior altura da torta no leito. O sólido presente no leito aumentou o tempo de filtração, mas contribuiu para a redução do teor de sólidos na água drenada. A drenagem foi finalizada após $7000 \mathrm{~min}$. Note que houve redução de $86 \%$ do volume de lodo colocado no leito de drenagem. Foi observado que a água não ficou empossada no leito e o volume de sólido que permaneceu no leito foi de 1,05 L.

Figura 3 - Volume de água drenada em função do tempo - ensaio 2.

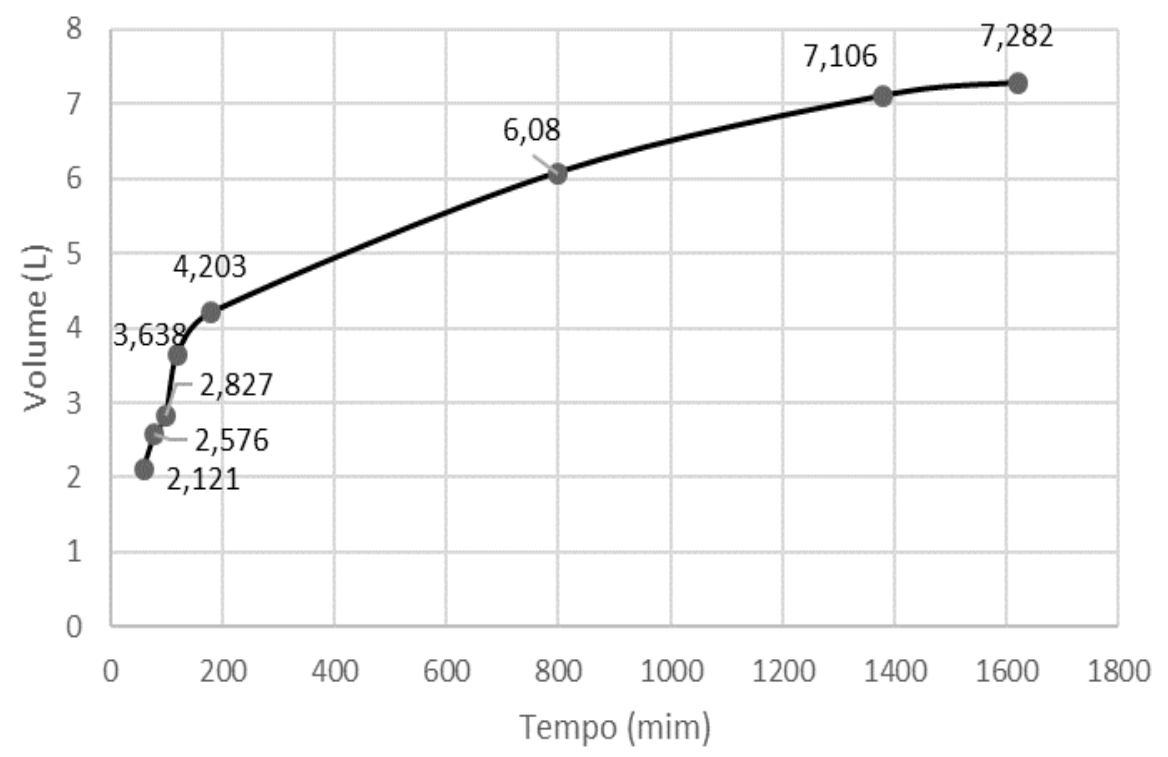

Fonte: Elaborado pelos autores.

Tabela 5 - Características da água drenada no ensaio 2.

\begin{tabular}{lll}
\hline Parâmetro & Resultado Obtido & Resolução Conama \\
\hline Turbidez & $64,2 \mathrm{NTU}$ & $\leq 40 \mathrm{NTU}$ \\
$\mathrm{pH}$ & 6,6 & Entre 6,0 e 9,0 \\
Sólidos Suspensos & $2,61 \mathrm{~g} / \mathrm{L}$ & $\leq 0,5 \mathrm{~g} / \mathrm{L}$ \\
Cor & Amarelo claro & incolor \\
\hline
\end{tabular}

Fonte: Elaborada pelos autores.

A Tabela 6 mostra os resultados de turbidez, pH, sólidos suspensos e cor da água drenada no terceiro ensaio. Note que nesse terceiro ensaio a água drenada apresenta maiores reduções nos valores de turbidez e sólidos suspensos. O leito de drenagem apresentou $99,36 \%$ de redução da turbidez e 99,91\% na remoção de sólidos suspensos.

Após os experimentos a manta geotêxtil foi retirada e o sólido removido e pesado. A massa total de sólido foi de $1,595 \mathrm{~kg}$. A concentração de alumínio na água drenada foi de $0,04 \mathrm{mg} / \mathrm{L}$. Essa concentração foi menor que a concentração de alumínio na água tratada $(0,05 \mathrm{mg} / \mathrm{L})$ e, também, muito menor que a concentração máxima de alumínio permitida $(0,20 \mathrm{mg} / \mathrm{L})$. 


\section{Revista Thema}

Figura 4 - Volume de água drenada em função do tempo - ensaio 3.

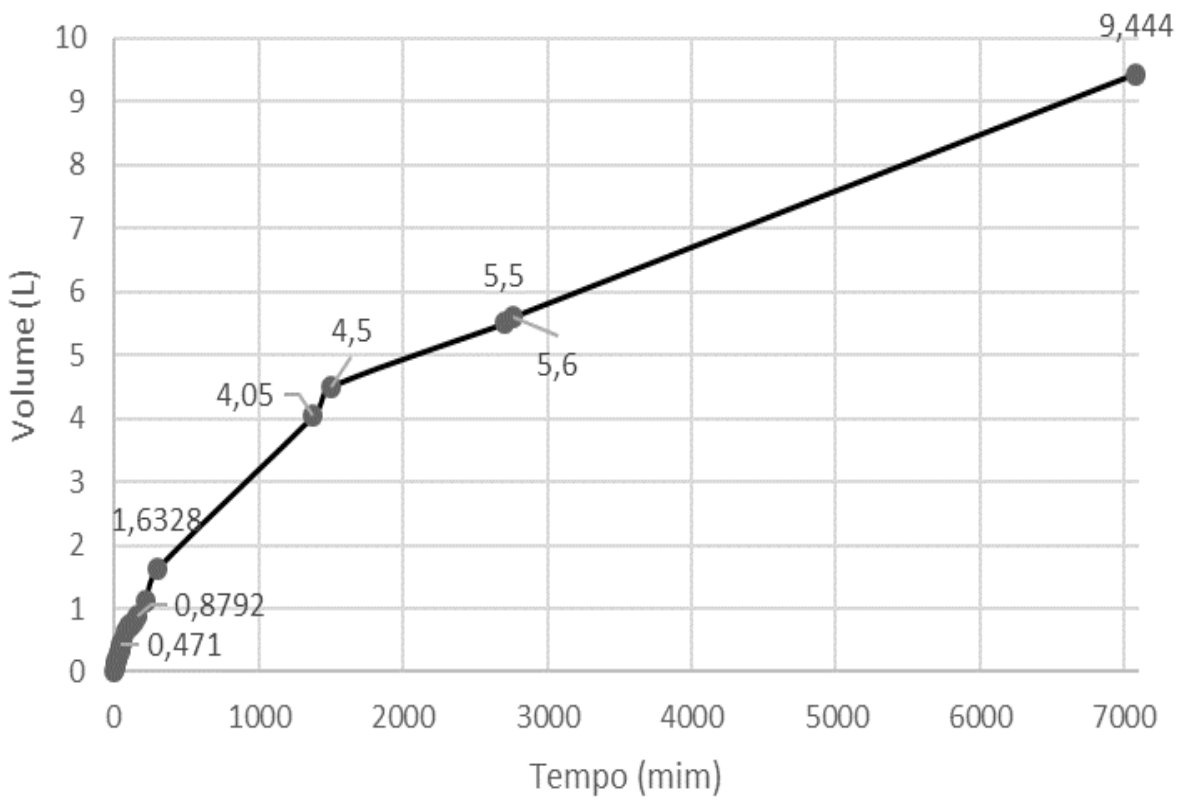

Fonte: Elaborada pelos autores.

Tabela 6 - Características da água drenada no ensaio 3.

\begin{tabular}{lll}
\hline Parâmetro & Resultado Obtido & Resolução Conama \\
\hline Turbidez & $2,74 \mathrm{NTU}$ & $\leq 40 \mathrm{NTU}$ \\
$\mathrm{pH}$ & 6,7 & Entre 6,0 e 9,0 \\
Sólidos Suspensos & $0,018 \mathrm{~g} / \mathrm{L}$ & $\leq 0,5 \mathrm{~g} / \mathrm{L}$ \\
Cor & incolor & incolor \\
\hline
\end{tabular}

Fonte: Elaborada pelos autores

\section{CONSIDERAÇÕES FINAIS}

Os resultados mostraram que o leito de drenagem reduziu entre $86-98 \%$ o volume de lodo da ETA. O leito de drenagem mostrou também alta eficiência para redução da turbidez (85-99\%) e sólidos suspensos (64-99\%). Além disso, foi observado que a água passou de amarelo escuro para incolor e o $\mathrm{pH}$ praticamente se manteve entre 6-7. Os ensaios no leito de drenagem mostraram que a torta colmatada contribuiu para redução da turbidez e de sólidos suspensos, no entanto, houve aumento no tempo de filtração. Pode-se concluir que o leito de drenagem é uma boa alternativa para o desaguamento de lodos provenientes de ETA, possibilitando a redução do volume de lodo e o reaproveitamento da água drenada com excelentes condições de turbidez e cor, que poderia ser recirculada no sistema de tratamento. $O$ sólido retido na manta geotêxtil foi facilmente removido para destinação do lodo e reutilização da manta. 


\section{REFERÊNCIAS}

ABNT. NBR-10.004: Resíduos Sólidos - Classificação. Rio de Janeiro: Associação Brasileira de Normas Técnicas, 2014.

ACHON, C. L.; BARROSO, M. M.; CORDEIRO, J. S. Leito de drenagem: sistema natural para redução de volume de lodo de estação de tratamento de água. Engenharia Sanitária e Ambiental, v.13, n.1, p.54-62, 2008.

ACHON, C. L.; BARROSO, M. M.; CORDEIRO, J. S. Resíduos de estações de tratamento de água e a ISSO 24512: desafio do saneamento brasileiro. Engenharia Sanitária e Ambiental, v.18, n.2, p.115-122, 2013.

BRASIL. Lei 12.305 de 02 de agosto de 2010: Política Nacional de Resíduos Sólidos. Brasília: Congresso Nacional, 2010.

EATON, A. D.; CLESCERI, L. S.; GREENBERG, A. E.; FRANSON, M. A. H. Standard methods for the examination of water and wastewater. 20. ed. Washington DC: American Public Health Association, 1998.

KURODA, E. K. et al. Drenagem/secagem de lodo de decantadores de ETAs em manta geotêxtil. Revista DAE, v.194, p.24-34, jan./abr. 2014.

RAFIQUE, M.; TAHIR, M. B.; SADAF, I. Nanotechnology: an innovative way for wastewater treatment and purification. Advanced Research in Nanosciences for Water Technology, p.95-131, 2019.

CONAMA. Resolução no 20, de 18 de junho de 1986: Dispõe sobre a classificação das águas doces, salobras e salinas do Território Nacional. Disponível em: http://www2. mma.gov.br/port/conama/legiabre.cfm?codlegi=43. Acesso em: 28 out. 2019.

SILVEIRA, C. Desaguamento de lodo de estações de tratamento de águas por leito de drenagem/secagem com manta geotêxtil. 2012. 137 f. Dissertação (Mestrado em Engenharia de Edificações e Saneamento) - Universidade Estadual de Londrina, Londrina, 2012.

WASSERMAN, J. C. et al. Evaluation of contaminants spreading from sludge piles, applying geochemical fractionation and attenuation of concentrations model in a tropical reservoir. Environmental monitoring and assessment, v.191, n.7, p.426, 2019. 